ticularly as no practical question of treatment by electricity required to be raised till after the lapse of a few weeks. Profuse purulent discharge still continued to come from both ears, in spite of the most careful application of the boracic acid treatment. Although every six hours the ears were syringed with a solution of boracic acid, then dried, and the powder insufflated, exuberant granulation tissue sprouted up from the walls of the external auditory canal and from the tympanic cavity.

Now that the child's general condition rendered it possible to ascertain the state of the hearing power, it was found that very great deafness existed, and that very loud speaking near to the head was essential in order that she might understand what was said. Her general condition continued to improve; nourishment was freely taken, and the strength gradually increased. At this stage she was conveyed back to town in order that the ears might receive the best attention, with the hope that their successful treatment might favour the disappearance of the facial paralysis. The boracic acid treatment, which is so frequently successful in purulent disease of the middle ear, having received a fair trial without apparent effect, I now employed, in addition, a solution of nitrate of silver (forty grains to the ounce of water) every day, using it in the manner first suggested by Schwartze-namely, dropping the solution into the ear, and then, after two or three minutes, neutralising it with a weak solution of common salt injected into the ear. After a week's trial, no good effect being apparent, the treatment by nitrate of silver was abandoned. Noticing that BurckhardtMerian strongly recommended an alcoholic solution of salicylic acid for purulent ear disease associated with diphtheria, I next tried this remedy, but found the pain and irritation to bo so great that it had to be given up.

Diluted rectified spirit was next employed in the strength of one-third of spirit and two-thirds of water. The following process was carried out every eight hours: (1) Careful syringing with a warm solution of boracic acid; (2) removal of all the moisture in the interior of the ear with absorbent cotton on a cotton holder; (3) instilling into the ear fifteen drops (warm) of the diluted spirit; (4) allowing it to remain in the ear, while the child lay on the opposite side, for fifteen minutes; (5) drying the canal with cotton, and then placing a plug of salicylicated cotton in the orifice of the ear. This treatment was, of course, applied to both ears. In addition, and in order to ensure still more thoroughly the complete expulsion of the purulent secretion Politzer's method of inflating the middle ear was performed once a day after the syringing. The nasal passages were also syringed daily with a tepid solution of chlorate of potash. The strength of the spirit was gradually increased to equal parts of water and rectified spirit, but when employed stronger than this the pain excited by it compelled us to return to the weaker form. This method of treatment very soon proved itself to be the most efficient. The discharge perceptibly diminished; the granulation tissue began to shrink and the hearing power became more acute. For five weeks after its first appearance the facial paralysis remained unaffected. Then the child showed more power of closing the eyelids, but probably another fortnight elapsed before the muscles of the cheek showed signs of mobility. First the naso-labial furrow deepened, and almost day by day some progress was observed in the recovery of the muscular power of the face. In about nine weeks from the time the paralysis was first observed it had completely passed off. There is no doubt that the returning power to the muscles of the face was co-incident with the improvement in the ear due to the spirit treatment. This improvement went steadily on, and in the course of four weeks from the beginning of the spirit treatment the granulation tissue had disappeared and the discharge reduced to a trace. When this was achieved very little of the tympanic membrane on either side was found to exist. The hearing was notwithstanding surprisingly good. In four months from the first attack of the fever the girl seemed almost as healthy as she had been before, though still somewhat dull of hearing. Her return to the country had no doubt contributed to this satisfactory result.

On May 15th, 1885, about eighteen months after the attack of scarlet fever, the condition of the hearing was as follows: Right ear-hearing distance for watch, 5 ; for Politzer's Hörmesser, $8 \mathrm{ft}$, Left ear-hearing distance for watch, "f ; for Politzer's Hörmesser, $9 \mathrm{ft}$. The whispered voice was heard in a quiet room at a distance of about $12 \mathrm{ft}$. with the eyes closed. The bone conduction of so:ind was on both sides better than the aerial. In each ear the only part of the tympanic membrane remaining was a piece of thickened membrana flaccida attached to the short process of the malleus. The handle of the malleus was not visible, but having lost the support of the tympanic membrane, it was probably drawn up by the tensor tympani muscle into the upper tympanic cavity. The inner wall of the tympanum was, owing to the loss of the tympanic membrane, clearly visible, and was seen to be lined by slightly thickened mucous membrane. The secreting process in the middle ear had long ago ceased. The throat still presented marks of the severity of the original disease. The base of the uvula was deeply indented, and the posterior edge of the soft palate somewhat serrated. The mucous lining of the posterior wall of the pharynx was also irregularly thickened. With the exception of some tendency to nasal catarrh, the child seemed to be in a condition of robust health.

Remarks. - 1. This case bears out what BurckhardtMerian has especially drawn attention to ${ }^{2}$-namely, that scarlet fever, when complicated with or followed by diphtheria, is apt to give rise to a most destructive type of disease of the ear. It is probable that in such cases there is a real propagation of the diphtheritic membrane along the Eustachian tube to the tympanic cavity, and even to the external auditory canal. We have not simply to deal with an ordinary collection of purulent secretion in the tympanic cavity, with rupture of the membrane and evacuation of the pus; we have rather to do with a rapidly destructive ulcerative process which, as is shown by this case, denudes the organ of the tympanic membrane in a very short time. There is reason to believe that scarlet fever alone does not produce such havoc; the addition of the diphtheritic poison seems to impart that destructive tendency to the ear complication which may terminate in deaf-mutism, or eren lead to a fatal issue.

2. From the favourable course of the facial paralysis in this case, we need not despair of recovery from this complication of purulent disease of the ear. In children, not only is the facial nerve, as it lies in its osseous canal on the inner wall of the tympanum, in close juxtaposition to the mucous membrane of the tympanic cavity, but the bony walls of this canal are very frequently defective when the neurilemma of the nerve is in actual contact with the mucous membrane. It is easy to understand how, with such an anatomical arrangement, the pressure of granulation tissue, swollen mucous membrane, or even of secretion, may produce paralysis of the facial nerve without ulcerative disease of the bone, and therefore without the same gloomy prognosis.

3. The recovery of fair hearing also illustrates a fact which is not unfrequently observed-namely, that fair hearing may exist even when the tympanic membrane is almost quite destroyed. What is of more importance than the presence of the tympanic membrane is a normal mobility of the fenestral structures. If these structures, with the stapes, are not thickened, bound down by adhesions, or subjected to pressure, fair hearing powrer may be enjoyed, although the membrane, with even the malleus and incus, should have been swept away.

4. This case also shows in a striking way the value of treatment by rectified spirit in purulent disease of the middle ear associated with granular excrescences.

\section{ON THE COMBINED ACTION OF COCAINE AND ATROPINE IN IRITIS.}

B I WALTER H. JESSOP, F.R.C.S., DEMONSTRATOR OF AXATOMY, ST. BARTHOLONEW'S FOSPITAL; SEMIOH ASSISTAYTI-SURGEON, CENTRAC LUNDON OPHTHALMIC HOSPITAL; OPH'THAMY SURGEON, PADDIYGTUS-GREEX CHIEDREX'S HOSPITAL.

Iv a paper on the Cocanised Eye, before the Opthalmological Society on Jan. 8th, 1885, I mentioned the use of the combination of cocaine and atropine in producing a very large dilatation of the pupil, and showed how this could be utilised in cases of iritis. Since then $I$ have been trying how best to use such a combination, but the expense of the drug till lately has restricted me in the number of my cases. I first tried using cocaine at the hospital after the patient

"Ucher den Scharlach in zeinen Beziehungen zum Gehơrorgan," von Alb. Burckhardt-Merian, in Volkmann's Sammlung, No. $1 \mathrm{~S}^{2}$. 
had been using atropine in the intervals of his visits, and hoping, perhaps, that the increased mydriasis produced might be kept up by the atropine used at home. A solution of atropine and cocaine was next tried when the patient could afford to pay for it, but finding how badly such a solution keeps, even with care, I gave it up for some dises which Messrs. Savory and Moore made for me. These discs contain $\frac{1}{200}$ grain of cocaine hydrochlorate and $\frac{1}{500}$ grain of atropine in each, and have answered all my requirements, being easy of application, constant in action, and very reliable. The following case in a healthy eye shows how quickly this combination produces an ad maximum dilatation of the pupil.

E. G-, aged six, pupils $5 \mathrm{~mm}$., equal, act well to light. and accommodation; $2 \cdot 24$ P.M., disc of cocaine and atropine in left eye ; $2 \cdot 29$ P.M., no effect on pupil, slight drooping of lower lid; $2 \cdot 34$ P.M., pupil $9 \mathrm{~mm}$. when shaded, $6 \mathrm{~mm}$. in bright light; 2.40 P.M., pupil $10 \mathrm{~mm}$., acting very slightly to light and accommodation; 2.42 P.M., pupil $11 \mathrm{~mm}$., does not act to light or accommodation. Therefore we have in eighteen minutes in this patient an ad maximuw dilatation of the pupil. To test the difference in time, and rapidity of dilatation of the pupil for the same amount of atropine, the following notes were taken on the same patient:-246 P.M., right eye, pupil $5 \mathrm{~mm}$., disc of atropine ( $\frac{1}{500} \mathrm{gr}$.) put in eye ; 258 P.M., no effect ; 3.4 P.M., no effect ; 3.17 P.M., pupil $8 \mathrm{~mm}$., does not act to light or accommodation; 322 P.M., pupil $9 \mathrm{~mm}$. ; 3.46 P.M., pupil $9.5 \mathrm{~mm}$, and did not increase. Thus in eighteen minutes atropine had no effect, and in one hour the pupil was only $9.5 \mathrm{~mm}$.

The following cases of iritis were treated at the Central London Ophthalmic Hospital :-

CASE 1.-B. B-_, aged twenty-seven, was admitted Dec. 30th, 1884. Syphilitic iritis; rash eight weeks ago; left eye inflamed six days. Left eye: great ciliary congestion ; iris discoloured; pupil $35 \mathrm{~mm}$.; irregular; on lower pupillary margin of iris is a gummatous mass; $\mathbf{T}+\mathbf{1}$. Ordered instillation of atropine, four grains to the ounce; cantharides plaster, 1 in. by 1 in.; compress; and solution of perchloride of mercury, one drachm three times a day.Jan. 2nd, 1885: Still in pain. Left eye: ciliary congestion ; gumma of iris the same; pupil $7 \mathrm{~mm}$. irregular; tension +1 . Two instillations of cocaine, 4 per cent. solution; pupil, $9 \mathrm{~mm}$., and regular, except below where gummatous mass is; some uveal pigment on capsule of lens, where other synechiæ were; great relief of pain. This patient continued under the same treatment, the gumma becoming absorbed; and the pupil under cocaine and atropine $9 \mathrm{~mm}$., regular, and no synechiæ to be seen even where the gumma was. He had one relapse of the iritis on Feb. 20th, but this cleared up with the same treatment, and on March 17th the note is:-Left eye: no congestion or pain ; pupil $9 \mathrm{~mm}$., a posterior synechia on the inner side, otherwise pupil quite regular; on lens capsule uveal pigment, especially below where the gumma lies.

CASE 2.-E. G---, aged forty-two, admitted Jan. 3rd, 1885. Rheumatic iritis; third attack. Has been under treatment with ointment of atropia, instillation of atropine four grains to the ounce, and leeches for three weeks, but is still in great pain. Left eye: circumcorneal zone, pupil $5 \mathrm{~mm}$. dilated, posterior syuechiæ on inner and under aspect; a little uveal pigment on inner side of pupil; $T+\frac{1}{2}$. After three instillations of 2 per cent. solution of cocaine the circumcorneal zone of the left eye was much lessened, pupil $8.5 \mathrm{~mm}$; ; numerous other small synechiæ were seen all round, and also much uveal pigment on capsule of lens. Patient spontaneously said that the eye felt much easier, and had quite lost pain.-Jan. 7th : Left eye, no circumcorneal zone, pupil $8 \mathrm{~mm}$., regular, though he has only been using atropine drops as before since last visit. He says that, though he has had severe rheumatic pains in joints, the eye has not been painful. On using 2 per cent. solution of cocaine left pupil was $8.5 \mathrm{~mm}$., and showed one small posterior synechia upwards and inwards.

CASE 3.-J. H_a aged thirty-two, was admitted March 3rd; syphilitic iritis; has been using atropine for one week. Left eye painful and congested; pupil $5.5 \mathrm{~mm}$., dilated; numerous synechiæ. Two instillations of cocaine, 2 per cent., and pupil $6.5 \mathrm{~mm}$. and regular.-6th : Has been asing atropine since last visit. Left eye: no pain, very little congestion; pupil $8 \mathrm{~mm}$, regular. Under cocaine, pupil $8.5 \mathrm{~mm}$; no synechiæ to be seen.

CASE 4.-C.S- - aged fifty-five, was admitted March 31st. Left eye inflamed for three weeks. Great ciliary con- gestion in left eye; iris discoloured ; pupil $35 \mathrm{~mm}$., sluggish T'ension normal. Ordered atropine drops (four grains to an ounce), and compress. - April 7th: Still pain. Left eye: circumcorneal zone; pupil $4.5 \mathrm{~mm}$, irregular; numerous posterior synechiæ. Two instillations of cocaine, 2 per cent. solution, and left pupil $7.5 \mathrm{~mm}$; only two synechiæ to be seen ; pain quite relieved.

CASE 5.-T. S-, aged thirty-six, admitted April 24th. Right eye inflamed and painful for fourteen days. Right eye: ciliary congestion; iris discoloured; pupil $4.5 \mathrm{~mm}$, sluggish, oval. Three instillations of solution of cocaine ( 2 per cent.) and atropine (four grains to the ounce). Right pupil, $7.5 \mathrm{~mm}$., showing two posterior synechiæ; ciliary congestion much lessened; great relief to pain. Ordered atropine drops.-28th: No pain. Right pupil, $75 \mathrm{~mm}$, regular. Two instillations of cocaine (2 per cent.), and right pupil $9 \mathrm{~mm}$., regular; no synechiæe to be seen.

CASE 6.-J. M- aged twenty-nine, admitted May 5th. Syphilitic iritis; three years ago primary sore; fifteen days right eye inflamed. Has been using atropine for one week. Right eye painful ; well-marked circumcorneal zone; pupi $6.5 \mathrm{~mm}$., dilated, regular; tension normal. Disc of atropine and cocaine put in ; fifteen minutes after much less pain and congestion; pupil $7 \mathrm{~mm}$., oval. A second dise was put in, and after ten minutes there was no pain in the right eye; pupil $8.5 \mathrm{~mm}$., round and regular. Ordered atropine drops.12th: Right eye still congested and painful; pupil $6.5 \mathrm{~mm}$ Disc of atropine and cocaine put in, and pupil $8.5 \mathrm{~mm}$. showing a posterior synechia to the inner side. Ordered dises of atropine and cocaine.-19th : Has been using the discs regularly since ordered, and has had no pain in the eye. Right eye: very little congestion; pupil $8.5 \mathrm{~mm}$., regular; no posterior synechiæe to be seen ; tension normal.

CASE 7. T. W-, aged thirteen, admitted May 15 th. Right eye inflamed for nine days. Right eye: much congestion; central corneal ulcer; great photophobia; pupil $2 \frac{1}{3} \mathrm{~mm}$. Ordered yellow ointment, with four grains of atropia, three times a day.-22nd : Right eye, still great congestion; corneal ulcer the same; pupil $5 \mathrm{~mm}$., regular; anterior chamber deep. 3.45 P.M., disc of cocaine and atropine; 355 P.M., pupil $6 \mathrm{~mm}$.; 4.5 P.M., pupil $9 \mathrm{~mm}$., irregular, small posterior synechia above. Ordered ointment of atropia, four grains to the ounce, three times a day.26th : Has had much less pain. Right eye: much less congestion; corneal ulcer smaller; pupil $8 \mathrm{~mm}$., regular; disc of cocaine and atropine, and pupil $9.5 \mathrm{~mm}$, regular.

CASE 8.-J.G-a, aged twenty-six, was admitted on June 19th. Gonorrhœa six months ago. Right eye affected then; for the last six days both eyes congested, and left eye very painful. Right eye: old iritis; pupil very irregular; numerous posterior synechiæ. Left eye: marked ciliary congestion ; pupil $35 \mathrm{~mm}$., sluggish. Ordered atropine drops three times a day.-23rd: Has been using the drops regularly in the left eye, but still has pain. Left eye: circumcorneal zone; pupil $5 \mathrm{~mm}$; four posterior synechiæ to be seen. Ordered discs of atropine and cocaine.-26th: No pain; scarcely any ciliary congestion. Left pupil $9.5 \mathrm{~mm}$.; one small posterior synechia above. To continue the discs. 30th: No pain; no ciliary congestion. Left pupil $9.5 \mathrm{~mm}$, regular; no posterior synechiæ to be seen.

CAsE 9.-F. R- - aged thirty-six, was admitted on June 26th, with syphilitic iritis. Six months ago he had. primary sore; three months ago a rash, sore-throat, and his left eye inflamed for six days, and very painful. Left eye: great ciliary congestion; anterior chamber muddy; pupil $3.5 \mathrm{~mm}$., irregular, and sluggish. $\mathrm{T}+\frac{1}{2}$. Under atropine the pupil was very irregular, only dilating in the upper half, a broad posterior synechia binding down the lower half of the pupillary border of the iris. Ordered cocaine and atropine dises three times a day, and mercurial treatment.30th: He has been using the discs four times a day, and after eight dises he says that the pupil became quite normal, and that he lost all pain in the eye. Left eye: very slight circumcorneal zone ; pupil $10.5 \mathrm{~mm}$., and regular; no adhesions visible; some uveal pigment just below the centre of the capsule of the lens; tension normal.-July 3rd: Tocontinue discs; no pain; no circumcorneal zone; left pupil $10.5 \mathrm{~mm}$, and regular.-21st: Four days ago he caught cold, and had a fresh attack of inflammation in the left eye, suffering great pain. He had finished all his discs, but obtained some yesterday, and after using four the pain was much relieved. Left eye: slight circumcorneal zone; pupil $10 \mathrm{~mm}$.; slightly irregular from three small posterior synechiæ at the inner side; tension normal.-24th: Left eye: no pain; no ciliary conges- 
tion; pupil $10.5 \mathrm{~mm}$; one small adhesion above and to the inner site.-28th : Left eye: no pain ; no congestion; pupil $10.5 \mathrm{~mm}$., and regular; no adhesions to be seen. To leave off discs.

CASE 10.-T. B-—, aged forty, admitted July 3rd. Says that every three years he has inflammation of eyes; no history of rheumatism, gout, ague, or venereal disease. Right eye: circumcorneal zone; pupil $3.5 \mathrm{~mm}$, very sluggish; ordered atropine drops.-7th : Right eye: still pain and circumcorneal zone; pupil $5 \mathrm{~mm}$., irregular; posterior synechiæ: tension normal; ordered dises of atropine and cocaine. 11th: no pain. Right eye: very little ciliary congestion; pupil $9 \mathrm{~mm}$; one posterior synechia below.-21st: Right eye : no pain, no congestion; pupil $9.5 \mathrm{~mm}$, regular; no synechiæe to be seen.

CAsE 11.-J. C-_-, aged twenty-nine, was admitted July 24th. Rheumatic iritis; left eye inflamed for fourteen days. Left eye: Great ciliary congestion and pain; pupil $4.5 \mathrm{~mm}$, sluggish ; $\mathrm{T}+\frac{1}{2}$; ordered atropine drops, but to get cocaine and atropine discs if possible.--28th: Used the atropine drops till two days ago, when the patient had great pain and could not sleep, so obtained the discs. He says that after one disc the pain was relieved in half an hour, and that he has been using them four times a day since. Left eye: no pain, very slight congestion, pupil $10 \mathrm{~mm}$., regular tension normal.-Aug. 4th: No pain. Left eye; pupil $10 \mathrm{~mm}$. regular. To leave off drops. Saw him a month afterwards; eye perfectly quiet; no relapse.

Remarks. - On looking over the notes of the above cases of iritis, treated by the combination of cocaine and atropine, we find the following constant and quickly attained results: great dilatation of the pupil, relief of pain, diminution of ciliary congestion, and decrease of intra-ocular tension when present. Now, in the active stages of iritis, as in inflammation of any other part, we have congestion of the vessels of the iris, and this gives rise to sluggishness, or even to contraction, of the pupil, followed often by posterior synechiæ. Therefore any treatment, to be successful, ought to be directed to relieving the iris of blood, and dilating the pupil as quickly as possible, so as to remove the pupillary edge of the iris from the central portion of the capsule of the lens. The pain, which is such a prominent symptom of iritis, is, I believe, due either to the turgid state of the vessels, giving rise to tension of the iris, and so to pressure on its nerves, or to the tension of synechiæ. Considering the physiological action of the drugs employed, we find that atropine produces mydriasis by paralysing the endings of the oculo-motor nerve and the unstriped muscular fibre of the iris, and, according to most observers, by stimulatng also the dilating mechanism of the pupil. The action of atropine on the bloodvessels of the iris is apparently of little importance, as any constricting influence would be quickly followed by dilatation. Cocaine, as I showed in a paper before the Royal Society on June 18th, 1885, acts by stimulating the endings of the mydriatic nerve of the eye, and also by constricting the small bloodvessels, thus producing a very large mydriasis, acting always to the movements of light and accommodation. Thus we see that neither drug produces alone all the effects necessary in the treatment of a case of iritis; but the combination of cocaine and atropine gives us all theseviz., an ad maximum dilatation of the pupil, constriction of the vessels of the iris, and inaction of the pupil to light and accommodation. The $a d$ maximum dilatation of the pupil produced by this combination keeps the pupillary border of the iris away from the capsule of the lens, preventing adhesions, and also breaks down synechiæ when formed by stretching them, and by constricting their vascular supply literally starves them. From these facts doubtless ensued the excellent results of cocaine and atropine in the cases above enumerated; but I would not, of course, suggest that this combination will have much effect in cases of old complete posterior synechiæ, but rather that we have in it a therapeutical remedy much more potent and certain in action in iritis than atropine. The rapid cessation of pain, which I have always seen follow the application of cocaine and atropine in iritis, enabled me to dispense with blisters and leeches in these cases.

WITH a view to prevent suicide from the top of Highgate Archway, the parish authorities of Hornsey and Islington have commenced to remove the parapet and to erect in its place strong iron railings $12 \mathrm{ft}$. high.
CASES ILLUSTRATING THE

SYMPTOMS AND TREATMENT OF CHRONIC ALCOHOLISM AS IT AFFECTS THE NERVOUS SYSTEM.

By W. B. HADDEN, M.D. LOND., M.R.C.P.,

DEMONSTRATOR OF MORBID ANATOMY AXD MEDICAL REGISTRAR TO

ST. THOMAS'S HOSPITAL, PHYSICIAN TO THE ROYAL HOSPITAL FOR CHILDREN AND WOMEN.

(Concluded from p. 611.)

THREE other cases closely resembling the one just described have come under my notice: two proved fatal, and in both cirrhosis of the liver existed. In one there was also acute tuberculosis. I find cirrhosis of the liver and tubercle associated in several of the recorded fatal cases of alcoholic paralysis. The main point of interest in the present case was the fever, which I was inclined to ascribe to the presence of tubercle. The satisfactory termination of the case practically disposed of this assumption which, nevertheless, was not altogether without warrant. Occasional pyrexia in these cases is not unfrequent; but I had never before seen a continued fever such as existed in this patient. During her convalescence another woman was admitted into the same ward, with almost exactly the same symptoms; but with her the fever is only occasional. She seems to be tending towards recovery.

M. G-, aged twenty-two, an actress, was admitted into St. Thomas's Home on August 30th, 1884. For the use of the case I am indebted to Dr. Edmunds, with whom I saw the patient several times. There is good reason to believe she had indulged in alcohol to excess. There was no history of syphilis. About nine months ago she used to sleep badly and dream a great deal. In the daytime she was nervous, and afraid to go out by herself. About this time she began to have fits. She used to scream, fall down, lose her senses, and then sleep. She has bitten her tongue and lips in the fits. Altogether she has had twelve or fourteen such attacks, at intervals varying from two to six weeks. For a month before admission she had violent vomiting, and, according to her mother, had not slept during this period. Two days before admission she became strange in her manner, had screaming fits, and did not know her friends.

On admission she could not answer when spoken to, and indeed could scarcely articulate. She did not know her friends or take notice of things, Her mind seemed quite a blank. She did not sleep at all the first night, but on the second she slept two hours and a half after two doses of chloral. At this time there were constant choreiform movements of the arms, but not of the face or legs. The latter were very thin and drawn up. The patellar tendon reflexes were absent. She passed her evacuations unconsciously. She spoke occasionally, but did not articulate distinctly. A vesicular eruption, coming out in crops, was observed on the palms and soles. The urine was free from albumen. There was no sign of visceral disease. On September 3rd the eyes were examined, but there was no optic neuritis. Her mental condition had improved. She pronounced her name plainly. She slept well without chloral, but her bowels acted under her during the night. On September 9th the rigidity of the legs was found to be much increased, and there was more wasting. Sensation was much impaired. When lifted out of bed she was quite unable to stand, the legs remaining bent. The arms were still affected by the choreiform movements. A bedsore had formed on the back. She was ordered five grains of iodide of potassium thrice daily. $A$ few days later an electrical examination was made. There was no response of the muscles of both legs with the interrupted current. With the continuous current there was no movement at all of the left leg. On the right side there was only a response with a rery strong current, and the contraction was better when changed from a descending to an ascending than vice ver'sâ. Rather more than a fortnight after admission her mind had become clearer, and she began to gain flesh. The legs were still drawn up and much adducted, the knees overlapping. She had regained sensation. There was almost complete paralysis. The jerky movements of the arms still persisted. She had now fair control over P 2 